\title{
Ambiente virtual: uma proposta para construção de material didático
}

\author{
Denise de Sena Pinho - Programa de Pós-Graduação em Educação em \\ Ciências e Matemática - PUCRS \\ denisenapuc@yahoo.com.br \\ Elisângela Ribas - Programa de Pós-Graduação em Educação em Ciências e \\ Matemática - PUCRS \\ elisribas@yahoo.com.br \\ Regis Alexandre Lahm - Programa de Pós-graduação em Educação em Ciências e \\ Matemática - PUCRS \\ lahm@pucrs.br
}

Resumo

Relato de Experiência

O propósito deste artigo é o de apresentar a construção de material didático, através de novas formas de relação e construção do conhecimento, utilizando uma ferramenta colaborativa e de co-autoria, o Wiki. Apresenta-se a dimensão social da aprendizagem e as características da ferramenta utilizada. Relata-se uma experiência realizada numa disciplina semestral de um curso de Licenciatura em Matemática, na modalidade a distância. A análise, a partir dos relatos dos alunos, demonstra a importância do uso de ferramenta que privilegie a comunicação e a interação entre os usuários, favorecendo, assim, o ensino e a aprendizagem.

Palavras - Chave : Interação - Wiki - Material didático

Virtual place: the propose to the build of the didactic material

\begin{abstract}
The propose of this article is to show the build of the didactic material using new way of relation and the knowledge, using a tool, the wiki. Presenting the social dimendsion of nowledge and the characteristic of this tool. Telling a experience realized in the sobject by the math course in the distance. The analise from the speach by the students, shows the importance among the users, facilitate the teach and learn.
\end{abstract}

Keywords: Interaction - Wiki - Didactic material

\section{Introdução}

Desde que as Tecnologias de Informação e Comunicação (TICs) começaram a se expandir pela sociedade, aconteceram muitas mudanças nas maneiras de ensinar e de aprender. "Na sociedade da informação, todos estamos reaprendendo a conhecer, a comunicar-nos, a ensinar; reaprendendo a integrar o humano e o individual, o grupal e o social”. (MORAN, 2005)

As TCIs, segundo Ponte, Oliveira e Varandas (2003), podem colaborar com o professor na criação de situações de aprendizagem estimulantes favorecendo, também, a diversificação das possibilidades de aprendizagem. As tecnologias ampliam a possibilidade de interação entre professores, alunos, objetos e informação para além do 
curto espaço da presença física do professor e alunos na mesma sala de aula. Vivemos uma mudança no cenário educacional, passando para uma aprendizagem pautada por paradigmas diferenciados dos tradicionais, ou seja, passamos a ter um ambiente on-line que permite a interação dos usuários, estimula a exploração e possibilita que o usuário faça a escolha de caminhos (navegação) que sejam adequados às suas necessidades e maneiras de aprender, facilitando, desse modo, a aprendizagem.

Nesse contexto, propomos a construção de material didático, para um curso de Licenciatura em Matemática, oferecido a distância. Utilizamos o ambiente Wiki, no qual podemos apoiar o trabalho de autoria coletiva, desencadeando uma motivação para novas formas de cooperar e possibilitando a criação de material didático colaborativo.

O objeto - material didático - foi projetado e construído para apoiar as aulas na disciplina de Geometria Espacial, na qual está sendo realizada uma pesquisa de estrado

junto aos alunos e professores. Assim, o objeto serviu de fio condutor para que corresse a interação entre o pesquisador e os sujeitos da pesquisa (futuros professores), estimulando o trabalho coletivo objetivando atingir um propósito comum promovendo práticas, através das quais os atores do processo de ensinar e aprender foram encorajados e estimulados a trabalhar em conjunto para a construção da aprendizagem e o desenvolvimento do conhecimento. Dessa forma, temos um cenário em que as práticas sociais, a colaboração e a cooperação são aspectos importantes para o favorecimento do processo da aprendizagem.

A análise elaborada através de relatos e discussões, realizados em chats e fórum, possibilitou constatar o quanto é importante pontuar a interação dos sujeitos com os outros sujeitos e o material didático.

\section{Dimensão social da aprendizagem}

Segundo Laaser (1997) não há teorias específicas para a Educação a Distância e, portanto, têm sido adotadas as teorias de ensino e aprendizagem já existentes. A atualidade aponta como tendência o uso flexível de estilos e teorias pedagógicas, visando atender à diversidade dos recursos e dos alunos presentes. As perspectivas evolutivas da educação a distância revelam a importância crescente de se promover novas propostas de ambientes de aprendizagem e interação.

Dando ênfase à constituição dessa proposta de ambiente, buscou-se enfatizar a construção coletiva e a interação para elaboração do material didático, para uso no ambiente virtual de aprendizagem, baseando-se, principalmente, Vygotsky (1998) e Jean Piaget (1973).

Segundo Vygotsky (1998), o desenvolvimento de atividades interpessoais possibilita mudanças cognitivas através da interação com a conseqüente reelaboração e reconstrução das idéias. De acordo com a teoria histórico-cultural do desenvolvimento humano, no processo interativo e social, a colaboração entre os participantes do ambiente é uma ação imprescindível para a aprendizagem, pois expressa a heterogeneidade presente nos grupos e ajuda o processo cognitivo implícito na interação e na comunicação. Tal movimento interativo implica uma relação sujeito-sujeito-objeto. Isto significa que é por meio dos outros que o sujeito estabelece relações com objetos de conhecimento, isto é, que a elaboração cognitiva se funde na relação com o outro. Há ainda a denominação de zona de desenvolvimento proximal onde Vygotsky (1998) considera a colaboração como um papel importante para o sujeito se desenvolver e aprender.

Piaget (1973) também reconhece as atividades em grupo como uma forma de facilitar o processo de aprendizagem. Ao atuar em uma coletividade, o sujeito revê seu 
pensamento, renuncia aos interesses individuais, passa a pensar em função do coletivo e isto acaba incitando a objetividade intelectual. Assim sendo, ele entende que os fatos mentais são paralelos aos fatos sociais, sendo o "eu" substituído pelo "nós" e as "ações" e "operações" pelas formas de "cooperação".

A dimensão coletiva permite que as interações se modifiquem em busca de uma ação coordenada, dando-se a cooperação. Esta é identificada como um processo em ação.Segundo Piaget (1973, p.105) “(...) Cooperar na ação é operar em comum, isto é, ajustar por meio de novas operações (qualitativas ou métricas) de correspondência, reciprocidade ou complementaridade, as ações executadas por cada um dos parceiros".

Portanto, promover condições para que pessoas separadas fisicamente possam elaborar materiais didáticos coletivamente, através de trocas de conhecimentos, é uma forma de viabilizar a relação entre professor/conteúdo/aluno.

\section{Ambiente para o material didático}

As conquistas sem fronteiras da navegação virtual, possibilitada pela rede de comunicação na Internet, em deslocamentos de tempo e espaço sem precedentes na história, mudaram profundamente as relações das pessoas com as tecnologias, suas necessidades, seus acessos à informação, à produção de conhecimento com pessoas de diferentes lugares, culturas, diferentes histórias. Pierre Lévy no livro "O que é virtual?", relata-nos uma argumentação sobre a virtualização.

Ela vive sem lugar de referência estável: em toda parte onde se encontrem seus membros móveis...ou em parte alguma. A virtualização reinventa uma cultura nômade, não por uma volta ao paleolítico nem às antigas civilizações de pastores, mas fazendo surgir um meio de interações sociais onde as relações se reconfiguram com um mínimo de inércia. Quando uma pessoa, uma coletividade, um ato, uma informação se virtualizam, eles se tornam 'não-presentes', se desterritorializam.(LÉVY,1996, p.20)

É relevante mencionar que os termos Wiki e WikiWiki são utilizados para identificar um tipo específico de coleções de documentos em forma de hipertexto ou software colaborativo usado para criá-lo. O termo WikiWiki originou-se do idioma havaiano e significa "super-rápido". Uma característica notável das ferramentas Wiki é a facilidade de edição e a possibilidade de criação de textos de forma coletiva e livre.

Segundo a estratégia Wiki, o conteúdo pode ser criado colaborativamente usando somente um navegador. Os softwares Wiki são livres e gratuitos. O ambiente Wiki utilizado foi configurado pelos autores, conforme indicado na Figura 1, com o endereço http://denisep.wikispaces.com/ . A ferramenta Wiki foi utilizada em conjunto com um curso criado na plataforma Moodle, um Course Management System (CMS), que permite a hospedagem de cursos pré-estruturados, no qual desenvolvemos atividades colaborativas, e a distância, com alunos do curso de Geometria Espacial, do curso de Licenciatura em Matemática, de uma universidade federal, no Estado do Rio Grande do Sul. 


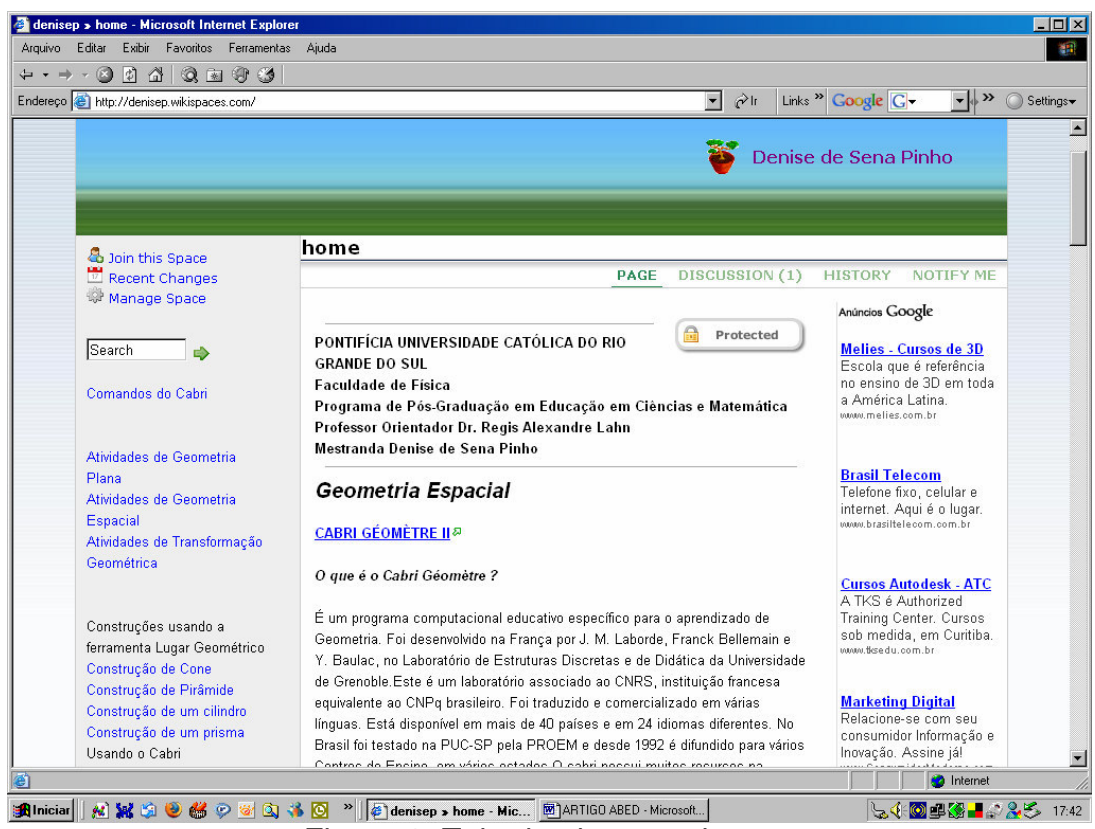

Figura 1. Tela de abertura do Wiki

O Wiki não dispõe de um design gráfico definido nem dispõe da habitual estrutura rígida para cursos virtuais. É um ambiente flexível, uma página em branco, em que as relações vão se estabelecendo com o uso. Ele contém apenas os componentes tecnológicos necessários para o estabelecimento, pelos usuários, do design gráfico e da estrutura de apresentação e funcionamento. Na Figura 2, apresentamos o espaço de inserção de conteúdos no ambiente.

A inserção de conteúdos no Wiki é feita de forma simples, os alunos também podem inserir, apagar, editar conteúdos, imagens, links, entre outras opções, a partir do próprio browser - aplicativo usado para visualizar páginas da Internet, permitindo a navegação a rede. Todas essas ações são registradas automaticamente e podem ser acessadas por todos os participantes.

Outras características, que levaram à escolha do Wiki: é não hierárquico - dá ênfase à cooperação, na possibilidade de todos os usuários inserirem ou excluírem documentos e demais informações, independente de sua condição no grupo; é transparente - identifica o registro de cada uma das alterações no sistema, indicando em tela quem o realizou e em que momento; é customizável - permite adequar o ambiente aos interesses e necessidades dos usuários, de acordo com a concepção pedagógica adotada; é um espaço que exige ética - há liberdade para qualquer ação dentro do ambiente, o que pressupõe critérios claramente definidos entre os membros do grupo; é de fácil articulação - permite aos usuários, de forma bastante simples, estabelecer links com sites de interesse do grupo e páginas pessoais; é reservado a grupos específicos o acesso é livre e restrito ao grupo, com utilização de senhas. 


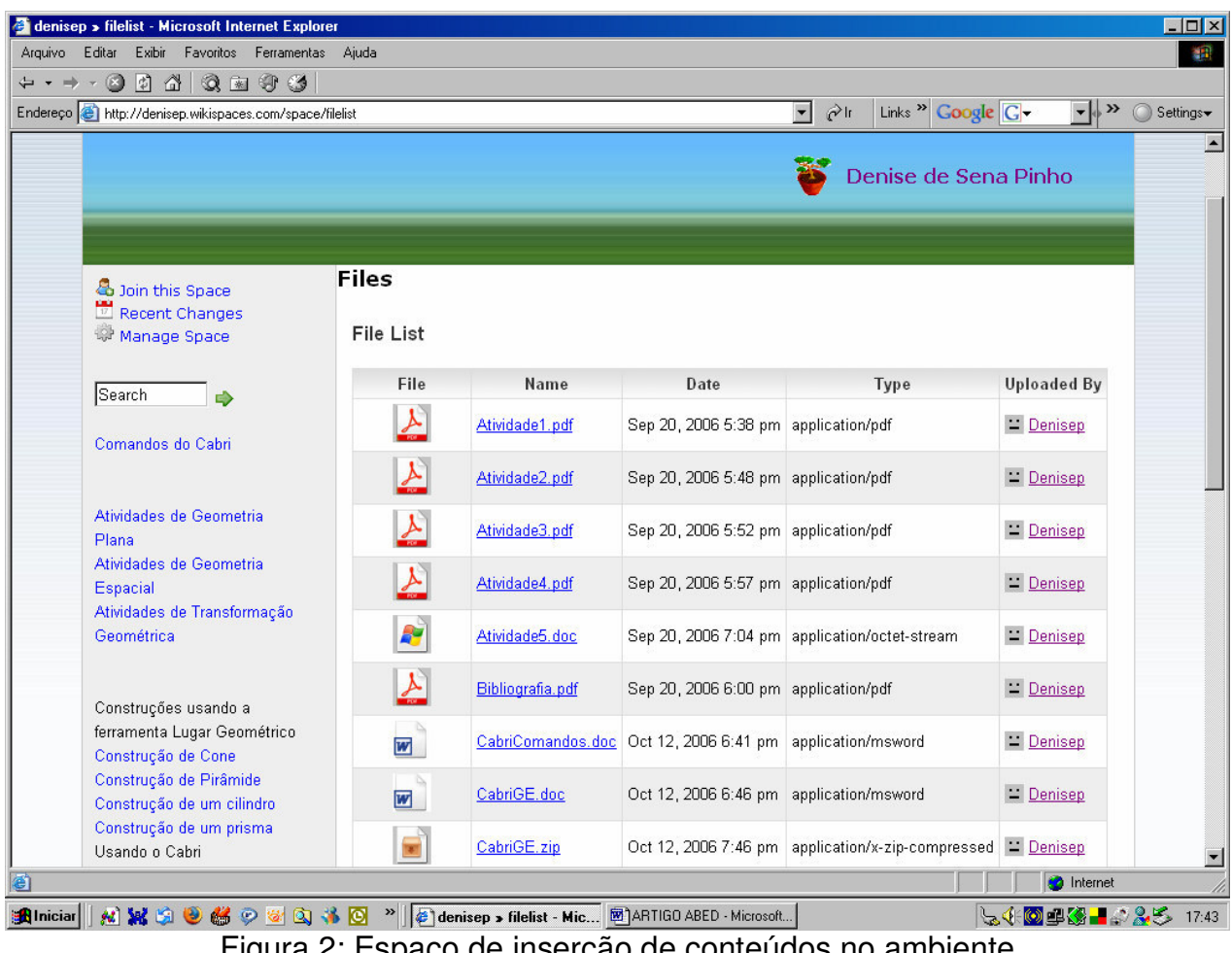

Figura 2: Espaço de inserção de conteúdos no ambiente

Por suas características, o Wiki funcionou como um repositório de material para estudo, cuja edição foi feita pelos próprios pesquisadores, mas com a contribuição dos alunos.

\section{Graduação na Educação a Distância (EaD)}

A carência de professores para a educação básica com a titulação em nível universitário, principalmente em Matemática, longe dos grandes centros, é grande. As cidades distanciadas das universidades sofrem com a falta de especialistas educadores com formação superior. Devido ao custo e à falta de tempo - geralmente os profissionais já trabalham nas escolas e não podem deixar suas turmas - os professores não podem se aperfeiçoar, gerando, assim, profissionais "leigos".

Educar é crer, realizar e validar na convivência, um modo particular de conviver. Isto sempre se realiza em uma rede de conversação que coordena o fazer e o emocionar dos participantes. Em um país, a natureza de qualquer atividade educativa é cumprir este dever na formação dos cidadãos do país. Em um país com interação democrática, isso significa entregar a cada cidadão elementos para um dever autônomo, social e ecologicamente responsável. (MATURANA, 1999, p.147).

De acordo com essa perspectiva, a EaD surge como possibilidade para atender o problema de dimensões continentais do território brasileiro, proporcionando a flexibilidade do acesso ao ensino - especialmente o ensino superior - numa perspectiva de democratização das oportunidades. A regulamentação da EaD foi introduzida no sistema educacional brasileiro com a Lei $n^{\circ} 9.394$ - Lei de Diretrizes e Bases da Educação Nacional - LDB, na qual, através do artigo 80, das disposições gerais, foram estabelecidas as determinações sobre a EaD: "o Poder Público incentivará o 
desenvolvimento e a veiculação de programas de ensino a distância em todo os níveis e modalidades de ensino, e educação continuada".

A proliferação de cursos EaD, no Brasil, está numa fase de crescimento, principalmente no Ensino Superior. Quinhentos e quatro mil pessoas, no país, usaram o ensino a distância em 2005, somente em faculdades autorizadas pelo Ministério de Educação. Na graduação e na pós-graduação, dobrou o número de estudantes matriculados nessa modalidade entre 2003 e 2004. Em 2003, havia 76769 alunos matriculados, no ano seguinte, o número saltou para 159366. Somando todos os níveis de ensino, o número de alunos passa de um milhão. Em Dezembro de 2005, a página WEB do MEC mostra 118 Instituições de Ensino Superior autorizadas a oferecer cursos de graduação, sequienciais e de lato-sensu. Algumas também oferecem cursos tecnológicos a distância. (MORAN, 2006).

Dentro desse contexto e considerando que os Ambientes Virtuais de Aprendizagem estão criando condições técnicas e motivadoras para a $\mathrm{EaD}$, ao mesmo tempo que estão provocando novos desafios em relação aos modelos tradicionais de ensino e de aprendizagem, sentimo-nos impulsionados para o desenvolvimento desta pesquisa, podendo, assim, legitimar o caráter social do trabalho e a contribuição científica que a mesma pode fornecer aos desafios educacionais do país.

Os autores pesquisaram junto a três cidades-pólo da Região Sul, do Estado do Rio Grande do Sul. Nos três pólos, os discentes, em sua maioria, têm idade superior a 24 nos, não possuem outro curso superior, trabalham na iniciativa privada ou pública em tempo integral, têm pouco tempo para se dedicar ao curso, o que serve como indicador para incentivar ainda mais a interação na construção do conhecimento.

\section{5 - Os resultados obtidos}

Para investigar a interação que proporcionou o material didático apresentado de maneira que sustentasse o desenvolvimento e engajamento dos alunos na construção de conhecimento, utilizou-se a análise dos diálogos realizados nos chats e nos fóruns enviados, aos pesquisadores, pelos alunos de cada pólo e suas postagens no ambiente Wiki. O primeiro contato dos alunos com o ambiente foi realizado no laboratório de cada pólo, com o auxílio da professora-orientadora da cidade-pólo, assessorando presencialmente, na cidade-sede a professora-tutora e, em outra cidade, um dos professores-pesquisador todos participando do chat. Foram realizados, chats em dias iferentes para melhor atender os alunos. Durante esses momentos, os alunos exploravam o ambiente e se familiarizavam com ele, tirando suas dúvidas e interagindo com os demais alunos e professores.

Em um segundo momento, marcamos uma aula presencial em cada cidadepólo, entre alunos e pesquisadores. Aos alunos interessados a postarem atividades foi dada uma senha. A interação dos participantes foi observada sob a ótica da modalidade de participação. Os depoimentos ajudaram a pensar a respeito da interação coletiva como arte do processo da educação apoiada em tecnologias de Internet. Eles permitiram uma primeira visão do comportamento dos sujeitos na discussão on-line: percebemos que geralmente há alunos que são mais propositivos, provocativos e outros que precisam ser instigados numa discussão on-line, revelando uma postura mais conservadora, decorrente da pedagogia tradicional, voltada mais para "o responder" do que para o exercício do questionamento. As colocações a seguir ilustram esse comportamento: 
"Estamos apreensivos, ainda estamos acostumados com cursos esquematizados, com temas tratados sistematicamente, e provas ou trabalhos ao final do curso para saber se o aluno "aprendeu ou não’. O aluno precisa assumir sua autonomia para melhorar sua aprendizagem."

"Sabemos que é importante descobrirmos as coisas sozinhos, mas o tempo é limitado e sentimos falta da professora, não para dizer tudo, mas para auxiliar, pois estamos acostumados a ter alguém para esclarecer nossas dúvidas, temos semanalmente uma aula presencial."

"Num primeiro momento fiquei muito preocupada, pois minha expectativa era de que fôssemos fazer um curso sobre como fazer figuras espaciais, e não de que já iríamos iniciar trabalhando num ambiente que ainda não conhecia (...)".

Os alunos declararam, durante os chats e os fóruns, a importância do material didático disponibilizado, como auxílio para organizar ou reorganizar suas aprendizagens, dando significado aos conceitos estabelecidos pelo conteúdo, pois até então só tinham acesso a material impresso (livro) para construírem ou reconstruírem seus conhecimentos.

A partir do momento em que foi oferecido o ambiente, alguns alunos começaram a aprofundar mais suas leituras e a participar mais ativamente das atividades nos ambientes virtuais, discutindo questões relativas ao conteúdo com seus colegas e professores, interagindo sobre o ambiente. Os depoimentos a seguir, demonstram essas atitudes:

“Já vi em um livro de Ensino Fundamental atividades sob representação espacial. (...) nós acabamos apenas fazendo os exercícios do livro que são pedidos e não discutimos o resto".

"Comecei a procurar na Internet sites sobre o Cabri e encontrei um muito interessante, pessoal, vejam: http://www.mat.ufrgs.br/ edumatec/software/softw.htm .”

"Empenhei-me bastante em postar atividades no ambiente. Em primeiro lugar porque algumas vezes construí no software Cabri a figura e no momento de passar para o Wiki não conseguia. O processo era desconhecido e tive que aprender (requereu muitas horas). Em segundo lugar, senti-me motivada em aprender, achei muito interessante de participar na construção de uma página na Internet”.

"O trabalho envolveu grande esforço, muita pesquisa, muita dedicação e algum cansaço, mas posso dizer que foi muito gratificante. A minha abrangência de conhecimento aumentou muito com esse trabalho".

Todos os depoimentos aqui retratados mostram a importância atribuída à atividade desenvolvida. Iniciativas como essa representa estratégias de ação possíveis de serem realizadas, nas Licenciaturas em Matemática, como forma de contribuir nas atividades educativas. Dessa forma, evidencia-se a aprendizagem na qual professores e alunos têm condições de serem autores de suas construções(re) de seus conhecimentos. Temos um processo que se instaura de forma individual e coletivamente. Nem só individual, nem só coletiva; nem só unidirecional, nem só como expressão de um único autor/ator, mas de forma cooperativa sem perder a unidade e ainda reforçando a autonomia do sujeito, na medida em que privilegia a alteridade na interatividade, a colaboração e a afetividade.

\section{6 - Considerações Finais}

Assim sendo, a proposta desta pesquisa evidencia uma posição acerca do ensino e da aprendizagem, da comunidade gerada nela, como um "abrir-se" a uma produção coletiva, assimétrica, na qual o professor tem um papel essencial, mas que, ao 
longo do tempo, vai modificando seus modos de viver e de se constituir, pois essa assimetria se desinstala com um pêndulo e, professor e aluno, passam a aprender e a ensinar um ao outro. (FREIRE, 1980; VYGOTSKY, 1984).

Portanto, a iniciativa de incorporação dessa atividade, que favoreceu a interação social, a cooperação e a colaboração na construção e exploração de material didático, para um curso a distância, revelou-nos a importância de que sejam exploradas (construídas) estratégias alternativas de aprendizagem.

Procedendo-se dessa forma, tem-se uma abordagem educativa com uma dinâmica interativa que promove um ir e vir constante e alternado, onde todos contribuem e são autores do processo de construção do conhecimento coletivo e individual - favorecendo para que ocorra uma aprendizagem significativa.

\section{Referências}

FREIRE, Paulo. Conscientização: teoria e prática da libertação: uma introdução ao pensamento de Paulo Freire. São Paulo: Moraes, 1980.

LAASER, Wolfram. Manual de criação e elaboração de materiais para educação a distância. Brasília. CEAD, Editora Universidade de Brasília, 1997.

LÉVY, Pierre. As Tecnologias da Inteligência: o futuro do pensamento na era da informática. Rio de Janeiro: Editora 34,1993.

.As árvores do conhecimento. São Paulo: Editora Escuta, 1995.

.O que é virtual? São Paulo: Editora 34, 1996.

LDB - Lei de Diretrizes e Bases da Educação Nacional - disponível em:

http://www.mec.gov.br/legis Acesso em: 12/04/2007.

MATURANA, Humberto. Uma nova concepção de Aprendizagem. Dois Pontos. Belo Horizonte, v.2,n.15, 1993.

UFMG, 1999.

Emoções e linguagem na educação e na política. Belo Horizonte: Ed.

e VARELA, F. De máquinas e seres vivos: autopoiese - a organização do

vivo. 3.ed. Porto Alegre: Artes Médicas.

MORAN, José Manuel. Tendências da educação online no Brasil In: RICARDO,

Eleonora Jorge(org.). Educação Corporativa e Educação a Distância. Rio de Janeiro: Qualitymark, 2005.

Marcos;

O que aprendi sobre avaliação em cursos semi-presenciais In: SILVA,

SANTOS, Edméa(Orgs). Avaliação da Aprendizagem em Educação. Online. São

Paulo: Loyola, 2006.

PIAGET, Jean. Estudos Sociológicos. Companhia Editora Forense: Rio de Janeiro, 1973.

A Equilibração das Estruturas Cognitivas: problema central do

desenvolvimento. Rio de Janeiro: Zahar, 1976.

PONTE, João Pedro da. OLIVEIRA, Hélia. VARANDAS, José Manuel. As novas

tecnologias na formação inicial de professores: Análise de uma experiência.

Disponível em: http://www.educ.fc.ul.pt/docentes/jponte Acesso em: 12/04/2007.

VYGOTSKY, Lev S. A formação social da mente. São Paulo: Martins Fontes, 1984.

VYGOTSKY, Lev S. Formação Social da Mente. 6.ed. São Paulo: Martins Fontes, 1998.

Wikipedia (Open Content Encyclipedia) está disponível em :

http://pt.wikipedia.org/wiki/Wikipedia Acesso em: 12/04/2007. 